\title{
New Estimates of Present-day Crustal/Land Motions in the British Isles based on the BIGF Network
}

\author{
D. N. Hansen, F. N. Teferle, R. M. Bingley \\ Institute of Engineering Surveying and Space Geodesy, \\ University of Nottingham, Nottingham NG7 2TU, UK
}

S. D. P. Williams

Proudman Oceanographic Laboratory,

Joseph Proudman Building, 6 Brownlow Street, Liverpool L3 5DA, UK

\begin{abstract}
In this study we present results from a recent reprocessing effort that included data from more than 120 continuous Global Positioning System (CGPS) stations in the British Isles for the period from 1997 to 2008. Not only was the CGPS network dramatically densified from previous investigations by the authors, it now also includes, for the first time, stations in Northern Ireland, providing new constraints on glacio-isostatic processes active in the region. In our processing strategy we apply a combination of re-analysed satellite orbit and Earth rotation products together with updated models for absolute satellite and receiver antenna phase centers, and for the computation of atmospheric delays. Our reference frame implementation uses a semi-global network of 37 stations, to align our daily position estimates, using a minimal constraints approach, to ITRF2005. This network uses a combination of current IGS reference frame stations plus additional IGS stations in order to provide similar network geometries throughout the complete time span. The derived horizontal and vertical station velocities are used to investigate present-day crustal/land motions in the British Isles. This first solution provides the basis for our contribution to the Working Group on Regional Dense Velocity Fields, 2007 - 2011 of the International Association of Geodesy Subcommission 1.3 on Regional Reference Frames.
\end{abstract}

Keywords Global Positioning System; Crustal Motions; British Isles

\section{Introduction}

There are two large-scale geophysical processes known to cause crustal motions in the British Isles. The first, the motion of the Eurasian plate due to plate tectonics, predominantly acts on the horizontal coordinate components with negligible effect on the vertical. The second, known as glacio-isostatic adjustment (GIA), is the on-going viscous response of the solid Earth to past changes in ice sheets and sea level. This process contributes a signal in both the vertical and horizontal components (e.g. Milne et al., 2006; Bradley et al., 2009).

The plate tectonics signal in the British Isles, which is considered part of the rigid interior of the Eurasian plate, is seen as motion in a northeasterly direction of approximately $23 \mathrm{~mm} / \mathrm{yr}$. The horizontal component of the GIA signal is primarily associated with the Laurentide ice sheet and is predicted to be in a northwesterly direction, with a magnitude that varies across the region and is thought to be of the order of $1-2 \mathrm{~mm} / \mathrm{yr}$. For the vertical component, the dominant GIA signal is associated with the BritishIrish ice sheet and the adjacent, significantly larger Fennoscandian ice sheet, resulting in subsidence on Shetland, uplift in most areas of Scotland and Northern Ireland, and subsidence in large areas of England, Wales, and Ireland on the order of 1-2 mm/yr.

\section{The BIGF Network}

The British Isles continuous GNSS Facility (BIGF) is funded by the UK's Natural Environment Research Council (NERC) and is operated at the University of Nottingham by the Institute of Engineering Surveying and Space Geodesy (IESSG). The continuous GNSS data are supplied to BIGF by a number of collaborators (see Acknowledgments). Although, the current BIGF network holds data for over 150 CGPS stations, with some dating back to 1996, only a few of these stations have been established with precise geodetic or geophysical applications in mind. Furthermore, most of these stations have only been in- 
stalled since about 2004 and others have been frequently moved or shutdown. In view of this, only about 30 stations were considered suitable for geophysical applications in recent publications which considered data up to 31 December 2005 (Bradley et al., 2009; Teferle et al., 2009; Woodworth et al., 2009). Furthermore, these 30 stations provided a fairly inhomogeneous station distribution, with a lack of stations in the geophysically interesting areas of Scotland and Northern Ireland.

During the recent re-processing effort the BIGF network, seen in Figure 1, was used. All stations with more than 2.5 years of data by 31 December 2008 were processed and this large data set was then reduced to a subset of stations which were thought to represent crustal/land motion. The selection procedure for these stations was based on a database of surface and bedrock geological data, obtained from the EDINA national academic data centre (see Acknowledgments), site photographs and monumentation data in the station log files. The selected stations were first chosen based on their time series length, greater than 6 years of continuous data or combined data for stations which have undergone small location changes. The selection was then restricted to stations connected directly to bedrock, or stations on buildings or structures which are connected to bedrock. Unfortunately, the majority of stations in Scotland have fewer than 6 years of data, and since this region is one of the most geophysically interesting areas of the British Isles, a dual-CGPS station analysis (Teferle et al., 2002) was carried out in order to include some of these stations. A full description of the station classification scheme can be found in (Hansen et al., 2009).

The result of the classification scheme was that 46 stations were concidered suitable for geophysical applications.

\section{Re-processing of the BIGF Network}

Daily double differenced solutions were computed from 1 January 1997 to 31 December 2008 using an in house modified Bernese GPS Software Version 5.0 (Dach et al., 2007). These solutions were obtained using the re-processed products (including satellite orbits and Earth orientation parameters) produced by (Steigenberger et al., 2006), as these were the only complete set of re-processed products available at the time of processing. Additionally, the processing strategy included the modeling of first order ionospheric effects, incorporated absolute satellite and receiver antenna phase centre models (Schmid et al.,

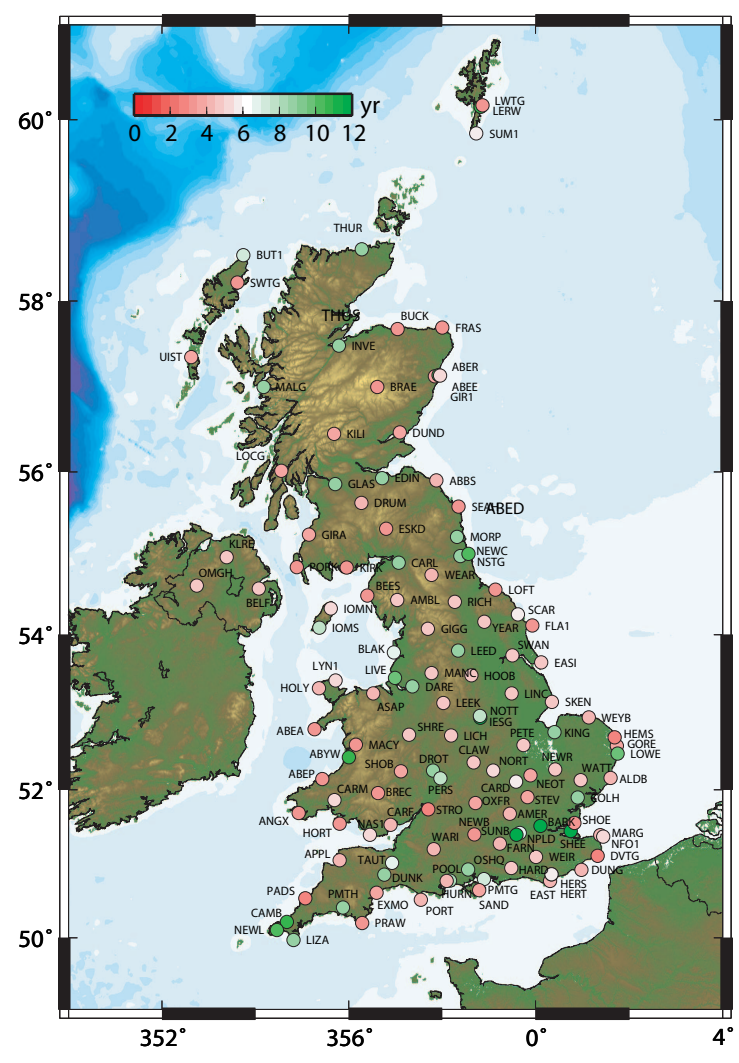

Fig. 1: BIGF network stations included in this reprocessing effort. The colour-coded circles indicate the length of the coordinate time series up to 31 December 2008 .

2007; Cardellach et al., 2007), and employed an apriori tropospheric model based on standard pressure and the Global Mapping Function (Böhm et al., 2006). Furthermore, corrections for solid Earth tides and ocean tide loading were made based on the IERS 2000 standards and coefficients from the FES2004 model respectively. Finally, we used 37 IGS stations, as shown in Figure 2, with well determined coordinates to align our daily coordinate results to ITRF2005 using a no-net translation minimal constraints approach (Altamimi et al., 2007).

The daily coordinate estimates (normal-equation files) were then combined to create a set of weekly SINEX solutions whose coordinates are computed for the mid-epoch of the week's data at each station. The resulting weekly coordinate time series were then analyzed using CATS (Williams, 2008) and Maximum Likelihood Estimation (MLE). This provides realistic uncertainties for all estimated parameters, e.g. linear rate, by accounting for both random and time-correlated noise in the time series. Ex- 


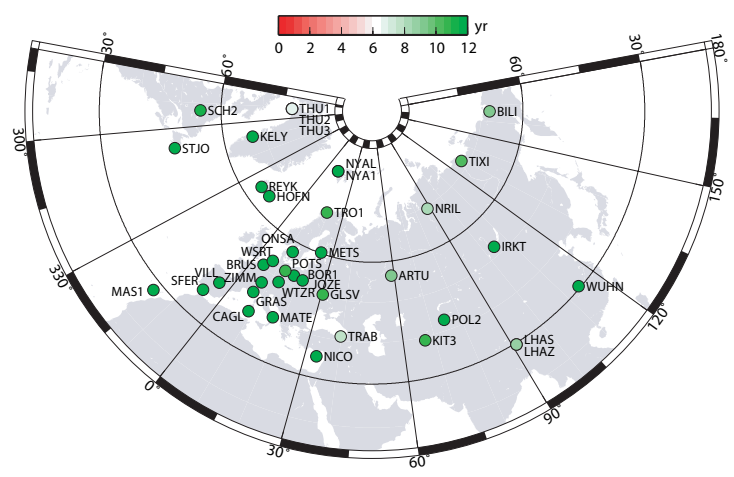

Fig. 2: The 37 IGS stations used for the reference frame implementation in this re-processing effort. The colourcoded circles indicate the length of the coordinate time series up to 31 December 2008, for comparison with Figure 1

ample results for IGS station HERS can be seen in Figure 3. It should be noted that great care was taken in order to account for all official coordinate offsets as reported in the IGS discontinuities file and for any extra equipment changes from IGS station information logs that produced a visible discontinuity in the coordinate time series.

\section{Crustal/Land Motion Estimates}

Crustal motion estimates can be obtained from the estimates of station velocity under the assumption that the CGPS stations only experience displacements due to the motions of the Earth's crust. If a station is affected by local and/or regional processes, e.g. the deformation of a man-made structure onto which the GPS antenna is mounted and/or natural compaction, then the estimates of station velocity can only provide land motion estimates, unless the effects of all active processes can be quantified. Therefore, vertical land motion can be considered being a combination of GIA and on-going natural compaction. These were assured through the station classification scheme outlined in Section 2. Furthermore, for the Nottingham region, the ground deformation pattern from a Persistent Scatterer Interferometry (PSI) analysis was also utilized to identify one station with an anomalous vertical station velocity (Hansen et al., 2009) and a few other stations with visibly anomalous vertical station velocities were also removed. This lead to a final set of 46 CGPS stations that were identified as experiencing crustal/land motions. A list of these stations together with their coordinates and velocity estimates can be obtained from the authors and is not given here for briefness.

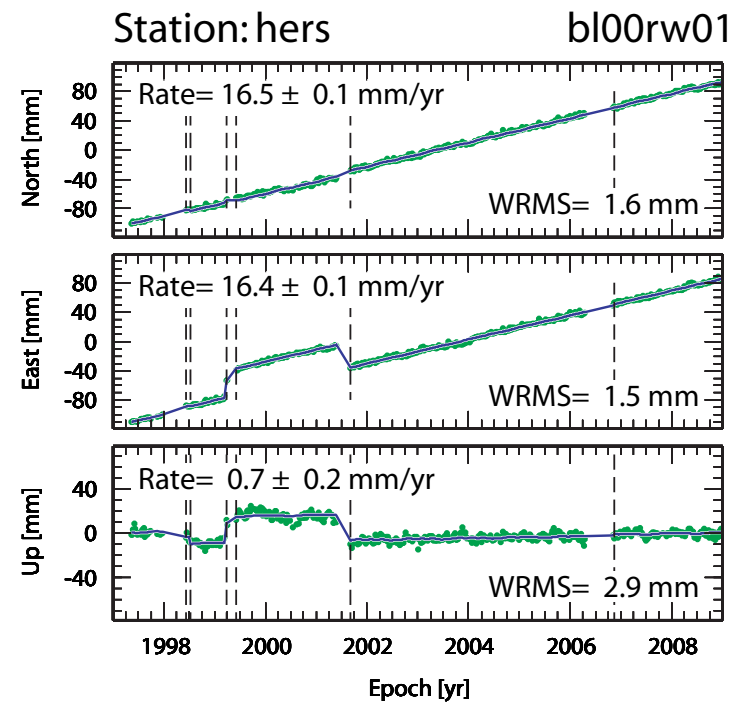

Fig. 3: Example of weekly coordinate time series for IGS station HERS. The dashed vertical lines indicate epochs at which an offset was modelled.

\subsection{Horizontal Motions}

As can be seen from Figure 4, overall, the apparent horizontal motions follow the predicted motions of the ITRF2005 plate motion model, with residual velocities being generally smaller than $1 \mathrm{~mm} / \mathrm{yr}$ with a RMS of $0.6 \mathrm{~mm} / \mathrm{yr}$. The residual velocities are apparently random with no discernible internal deformation and, as their magnitude is similar to the predicted horizontal motions associated with the GIA process, it is at this stage not possible to draw any conclusions without further investigations.

\subsection{Vertical Motions}

As can be seen from Figure 5, in general, the apparent vertical crustal motions confirm the expected pattern of subsidence on Shetland, uplift in most areas of Scotland and Northern Ireland, and subsidence in large areas of England and Wales. This suggests that the pattern of present-day vertical crustal/land motions based on geodetic data is largely consistent with the pattern of vertical crustal/land motions based on Holocene sea-level data. Furthermore, the inclusion of the CGPS stations in Northern Ireland, not available in Bradley et al. (2009) or Teferle et al. (2009), defines the westerly boundary of the GIA-induced uplift over Scotland and Northern Ireland, which improves the geodetic constraints for future GIA models for the British Isles.

Figure 5 shows maps of vertical crustal motions 

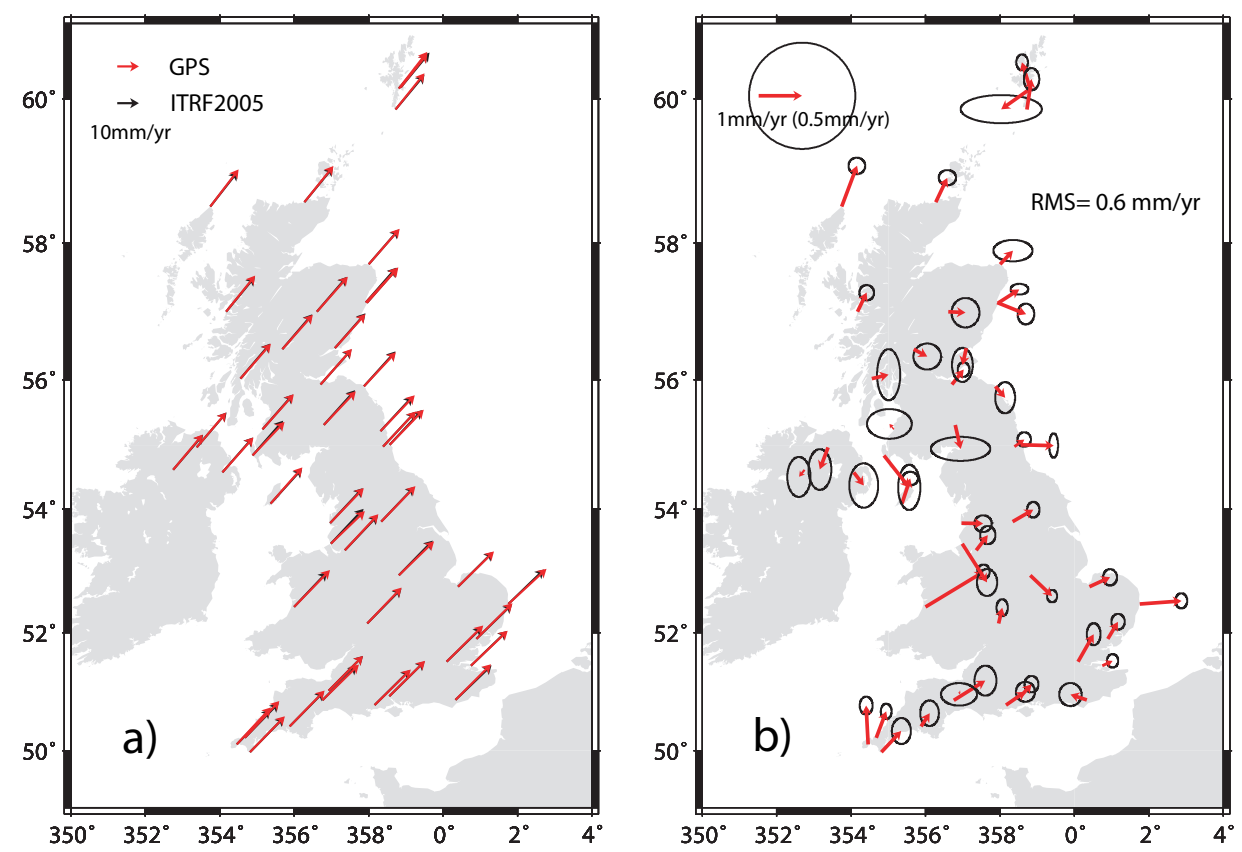

Fig. 4: Absolute (a) and residual (b) horizontal station velocities for the 46 selected CGPS stations. The residual station velocities were obtained by subtracting the ITRF2005 plate motion model velocities from the absolute horizontal station velocities.

derived from the vertical station velocities as obtained in ITRF2005 and from those in ITRF2005 then aligned to absolute gravity (AG) following Teferle et al. (2009). In particular, this alignment is achieved by computing the weighted mean difference between the vertical station velocity estimates from CGPS and AG which is then subtracted from the CGPS estimates to form AG-aligned CGPS estimates of vertical crustal motions. These are considered as giving a more realistic picture of the uplift/subsidence pattern due to the uncertainties associated with the reference frame implementation of this study and the systematic effects in the ITRF2005 vertical velocity estimates (Altamimi et al., 2007).

\section{Conclusions}

We have re-processed the CGPS data from over 120 stations in the BIGF network for the period from 1997 to 2008 and produced associated weekly SINEX solutions. The analysis of the derived coordinate time series showed that currently only 46 CGPS stations provide station velocity estimates that can be interpreted as present-day crustal/land motions. This represents an increase in the number of CGPS stations in the British Isles considered useful for geophysical applications and an improvement in the ho- mogeneity of the network in Scotland and Northern Ireland compared to previous studies. Further work is required to analyze the horizontal velocity field and to move from a semi-global to a global reference frame implementation. For now, however, the cumulative SINEX solution from this re-processing effort will form BIGF's first contribution to the Working Group on Regional Dense Velocity Fields, 20072011 of the International Association of Geodesy Subcommission 1.3 on Regional Reference Frames.

\section{Acknowledgements}

The work presented was partly funded through the UK Department for Environment, Food and Rural Affairs (Defra), the Environment Agency and the Natural Environment Research Council Strategic Ocean Funding Initiative grant NE/F012179/1. BIGF (www.bigf.ac.uk) acknowledges its data providers: Defra, Environment Agency, IESSG, Land and Property Services Northern Ireland, Leica Geosystems Ltd., Met Office, National Physical Laboratory, NERC Proudman Oceanographic Laboratory, NERC Space Geodesy Facility, Newcastle University, and Ordnance Survey of Great Britain. The authors are also thankful to the IGS community for provision of all other CGPS data and related GPS 


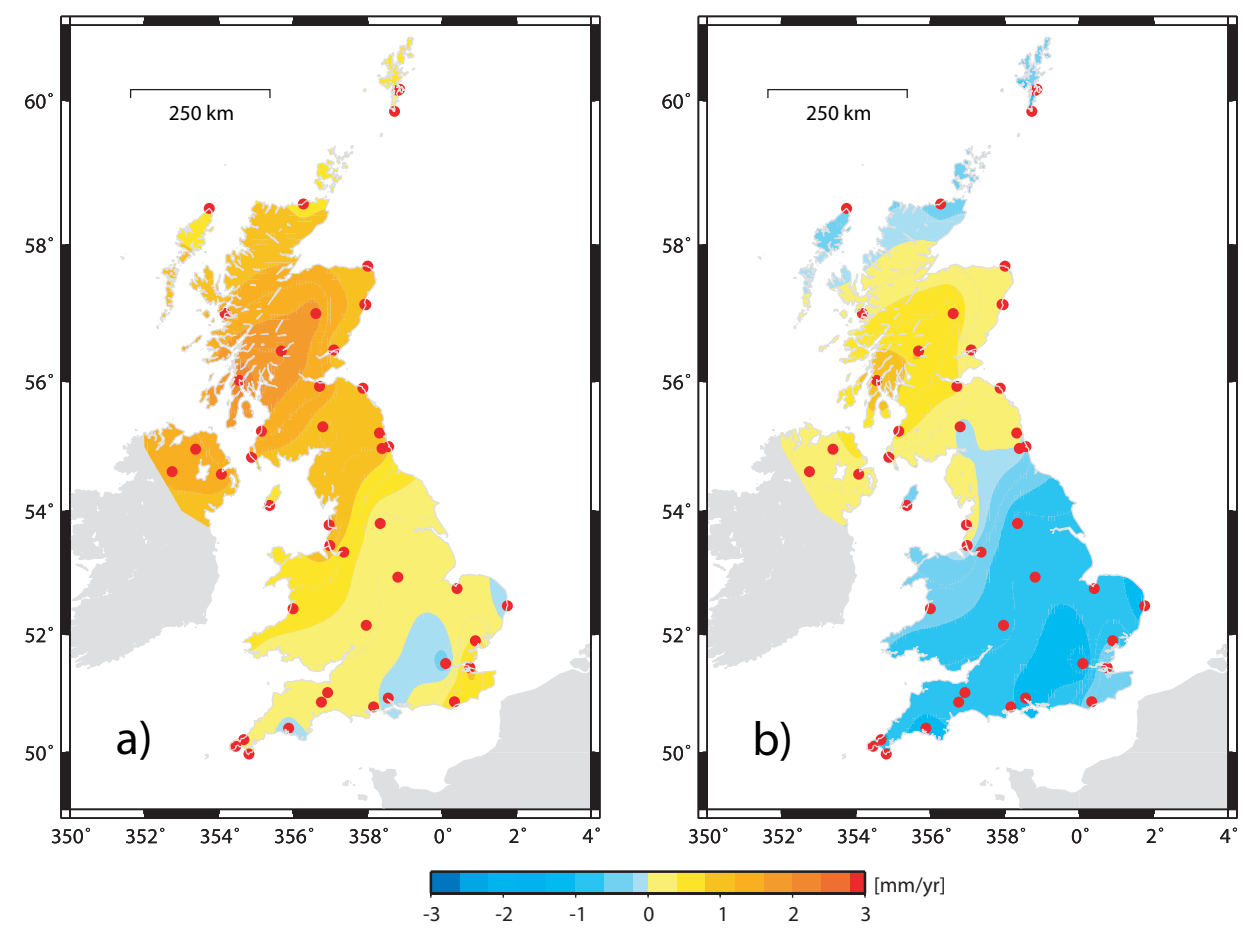

Fig. 5: Maps of vertical crustal motions based on the 46 selected CGPS stations for (a) CGPS in ITRF2005 and (b) CGPS in ITRF2005 then aligned to AG.

products (Beutler et al., 1999), and EDINA JISC national academic data centre based at the University of Edinburgh, and the British Geological Survey.

\section{References}

Altamimi, Z., Collilieux, X., Legrand, J., Garayt, B., \& Boucher, C. (2007) ITRF2005: A new release of the International Terrestrial Reference Frame based on time series of station positions and Earth Orientation Parameters, Journal of Geophysical Research, 112, B09401, doi: 09410.01029/02007JB004949.

Beutler, G., Rothacher, M., Schaer, S., Springer, T.A., Kouba, J. \& Neilan, R.E. (1999) The International GPS Service (IGS): An Interdisciplinary Service in Support of Earth Sciences, Advances in Space Research, 23, 4, 631-653.

Böhm, J., Niell, A., Tregoning, P., \& Schuh, H. (2006) Global Mapping Function (GMF): A New Emperical Mapping Function Based on Numerical Weather Model Data, Geophysical Research Letters, 33, 7, L07304.

Bradley, S.L., Milne, G.A., Teferle, F.N., Bingley, R.M. \& Orliac, E.J. (2009) Glacial Isostatic Ad- justment of the British Isles: New Constraints from GPS Measurments of Crustal Motion, Geophysical Journal International, 178, 1, 14-22.

Cardellach, E., Elosegui, P., \& Davis, J. L. (2007) Global distortion of GPS networks associated with satellite antenna model errors, Journal of Geophysical Research, 112, B07405, doi:07410.01029/02006JB004675.

Dach, R., Hugentobler, U., Fridez, P., \& Meindl, M. (Eds.) (2007) Bernese GPS Software Version 5.0, 612 pp., Astronomical Institute, University of Bern, Bern.

Hansen, D.N., Teferle, F.N., Bingley, R.M., Leighton, J., \& Williams S.D.P. (2009) On the challenges of measuring Glacio-isostatic Ajustment in the British Isles using geodetic techniques, Physics and Chemistry of the Earth, manuscript in preparation.

Milne, G.A., Shennan, I., Youngs, B.A.R., Waugh, A.I., Teferle, F.N., Bingley, R.M., Bassett, S.E., Cuthbert-Brown, C., \& Bradley, S.L. (2006) Modelling the Glacial Isostatic Ajustment of the UK region, Philosophical Transactions of the Royal Society, 364, 931-948, doi:10.1098/rsta.2006.1747. 
Schmid R., Steigenberger, P., Gendt G., Ge M., Rothacher, M. (2007) Generation of a consistent absolute phase-center correction model for GPS receiver and satellite antennas, Journal of Geodesy, 81, 12, 781-798.

Steigenberger, P., Rothacher, M., Dietrich, R., Fritsche, M., Rülke, A. \& Vey, S. (2006) Reprocessing of a Global GPS Network, Journal of Geophysical Research, 111, B05402, 10.1029/2005JB003747.

Teferle, F.N., Bingley, R.M., Dodson, A.H.,\& Baker, T.F. (2002) Application of the dual-CGPS concept to monitoring vertical land movements at tide gauges, Physics and Chemistry of the Earth, 27, 32-34, 1401-1406.

Teferle, F. N., Bingley, R.M., Orliac E.J., Williams, S.D.P., Woodworth, P.L., McLaughlin, D., Baker, T.F., Shennan, I., Milne, G.A. \& Hansen, D.N. (2009) Crustal Motions in Great Britain: Evidence from Continuous GPS, Absolute Gravity and Holocene Sea Level, Geophysical Journal International, 178, 1, 23-46.

Williams, S.D.P. (2008) CATS: GPS coordinate time series analysis software, GPS Solutions, 12, 147153, 110.1007/s10291-10007-10086-10294.

Woodworth, P. L., Teferle, F. N., Bingley, R. M., Shennan, I., \& Williams, S. D. P. (2009) Trends in UK mean sea level revisited, Geophysical Journal International, 176, 1, 19-30. 